\title{
Distracted by relatives: Effects of frontal lobe damage on semantic distraction
}

\author{
Anna L. Telling *, Antje S. Meyer, Glyn W. Humphreys ** \\ Behavioural Brain Sciences, School of Psychology, University of Birmingham, UK
}

\section{A R T I C L E I N F O}

\section{Article history:}

Accepted 10 May 2010

\section{Keywords:}

Frontal lobes

Semantic interference

Visual search

Selection

\begin{abstract}
A B S T R A C T
When young adults carry out visual search, distractors that are semantically related, rather than unrelated, to targets can disrupt target selection (see Belke, Humphreys, Watson, Meyer, \& Telling, 2008; Moores, Laiti, \& Chelazzi, 2003). This effect is apparent on the first eye movements in search, suggesting that attention is sometimes captured by related distractors. Here we assessed effects of semantically related distractors on search in patients with frontal-lobe lesions and compared them to the effects in age-matched controls. Compared with the controls, the patients were less likely to make a first saccade to the target and they were more likely to saccade to distractors (whether related or unrelated to the target). This suggests a deficit in a first stage of selecting a potential target for attention. In addition, the patients made more errors by responding to semantically related distractors on target-absent trials. This indicates a problem at a second stage of target verification, after items have been attended. The data suggest that frontal lobe damage disrupts both the ability to use peripheral information to guide attention, and the ability to keep separate the target of search from the related items, on occasions when related items achieve selection.
\end{abstract}

() 2010 Elsevier Inc. All rights reserved.

\section{Introduction}

In visual search tasks participants are asked to decide whether a pre-specified target is present on the screen. Many theories assume that search is guided to a target by an "attentional template" held in working memory. Evidence for such a template comes from a number of sources. Chelazzi, Miller, Duncan, and Desimone (1993) trained monkeys to make a saccade to an item in a search display that matched a stimulus held in working memory (using a match to sample task). They found that cells in the inferior temporal lobe responding to the cued item maintained their activity during the interval between the cue and the search display, with the cells showing an enhanced rise in activation when the cued item re-appeared in the search display. Chelazzi et al. proposed that the activity maintained during the interval between the cue and the display represented a template that biased activity in earlier cortical regions to favor features consistent with the target.

Evidence for effects of top-down guidance on human search comes from a number of sources. For example, several investigators have reported asymmetries in visual search, with search tasks

\footnotetext{
* Corresponding author. Address: School of Psychology, The University of Birmingham, Edgbaston, Birmingham B15 2TT, UK. Fax: +44 (0)121 414489.

** Corresponding author. Address: School of Psychology, The University of Birmingham, Edgbaston, Birmingham B15 2TT, UK. Fax: +44 (0)121 414489.

E-mail addresses: anna.telling@nottingham.ac.uk (A.L. Telling), g.w.humphreys@ bham.ac.uk (G.W. Humphreys).
}

varying in difficulty according to which item is the search target and which is the distractor (e.g., a large target versus small distractors generates efficient search, whereas a small target amongst large distractors generates inefficient search; Wolfe (1998)). Hodsoll and Humphreys (2001) showed that this search asymmetry was modulated by fore-knowledge of the target: the asymmetry was larger when participants knew what they were searching for relative to when they searched for a target that was the odd one out (see also Hodsoll \& Humphreys (2005), for similar evidence from orientation search asymmetries). Hodsoll and Humphreys proposed that the search asymmetry was partially dependent on the match between the stimulus and the search template (some stimuli are matched more quickly than others) and not just on bottom-up differences between the stimuli.

Moores et al. (2003) provided other evidence for a template by assessing the effects of semantic distractors on search. They asked participants to search for a familiar target object (e.g., motorbike) and, on some trials, presented semantic distractors in the display (e.g., motorbike helmet). They found that reaction times were slowed on trials when semantic distractors were present. On targetabsent trials in particular, the first eye movement tended to go to the semantically related distractor rather than to unrelated distractors. These data suggest that activation of a memory template for a target also excites the re-presentations of related items, which can then guide search to matching (but in this case, distractor) stimuli. In the present paper, we use data from patients with frontal-lobe lesions to probe-apart the different processes involved in guiding search to targets. In particular, using the procedure of 
Moores et al. (2003) we examine whether, in addition to any effects of related distractors on the initial stages of selection, there are effects at later stages in which any selected stimuli are compared with target-related templates. At what stage(s) can semantic information about the stimuli be accessed to influence target selection and how is this affected by damage to the frontal lobes? We present data suggesting that although there are effects of targetdistractor relatedness at both stages and across patient and control groups, frontal lobe damage alters: (i) the initial gathering of peripheral information that guides the first stages of target selection (which is independent of target-distractor relatedness) and (ii) the later process of target identification following the orienting of attention to a stimulus (which is affected by target-distractor relatedness).

\section{Effects of frontal lobe damage on search}

Adequate functioning of the frontal lobes is necessary for visual search (De Fockert, Rees, Frith, \& Lavie, 2004; for reviews see Corbetta \& Shulman, 2002; Kanwisher \& Wojciulik, 2000). In an fMRI study of healthy participants, Donner et al. (2000) found that the frontal eye fields (FEF) showed increased activation during conjunction search when compared to feature search. FEF activation was linked to the selection of search targets. The necessary involvement of the FEFs in search is supported by results using rTMS. Muggleton, Juan, Cowey, and Walsh (2003) found that, compared to a no-stimulation baseline, TMS over the FEF led to more false positive errors during conjunction search. No differences were found between the TMS and no TMS conditions for a feature search task, and intermediate differences in error rates occurred for an interleaved feature search task where target and distractor items varied across trials. It was concluded that the FEFs were necessarily involved in visual search, playing a particularly strong role when the target was not very salient.

The control of visual search is not restricted to the FEF, however. A wider requirement of the frontal lobes has been implicated in singleton search using fMRI and in experiments examining the interplay between visual selection and working memory. In their fMRI experiment, Lavie and de Fockert (2006) found evidence for increased dorsolateral frontal activity during search for a target in the presence (relative to the absence) of an irrelevant singleton distractor. They linked frontal lobe involvement to the requirement to suppress the salient distractor. Converging evidence comes from neuropsychological studies. Kumada and Hayashi (2006) studied a patient with frontal-temporal lobe brain damage, YW, and compared his results to normal controls. Participants either searched for a color or orientation-defined target amongst non-targets (no singleton condition) or for targets in the presence of a singleton distractor (differing in color or orientation from the other items present). YW's search RTs increased abnormally for the singleton compared to the no singleton condition. Kumada and Hayashi argued that YW's ability to select the target over the singleton was impaired due to poor top-down 'weighting' of the stimulus properties defining the target. Under these conditions singleton distractors competed strongly with targets and sometimes won the competition for selection.

Zihl and Hebel (1997) also reported problems in the planning of scan paths across dot patterns in patients with frontal damage and linked this to a working memory deficit. Problems in task control based on the active maintenance of working memory re-presentations could impact on search in various ways. For example, there might be less top-down control from a template of a target held in working memory, or there may be an impaired re-presentation of previously inspected locations so that search becomes more generally disorganized.
However, the requirement of frontal lobe functioning for competent search has not been observed universally. For example, Humphreys, Hodsoll, and Riddoch (2009) reported no difference between patients with frontal-lobe lesions and age-matched controls when search slopes were examined for feature and conjunction search tasks. They used brief presentation conditions, where working memory load may be reduced. The data suggest that search can be relatively normal when working memory is not loaded (see also Walker, Husain, Hodgson, Harrison, \& Kennard, 1998).

The relation between WM and visual search through small arrays was examined by Soto, Humphreys, and Heinke (2006). They found increased effects of irrelevant objects held in working memory on search in frontal patients compared with age-matched controls. They had participants hold an item in memory prior to carrying out a search task. The search task required participants to point to a tilted line target amongst vertical line distractors, and an irrelevant shape surrounded each line. Control participants were slowed in initiating saccades to the target when the memory item re-appeared surrounding a distractor in the search display, and the likelihood that the first saccade went to the target, rather than the distractor was also reduced. Soto et al. reported that these effects were equivalent in frontal patients and controls, indicating that the influence of the working memory on the initial stages of selection was relatively normal. Nevertheless, the patients made more errors when the memory item re-appeared around a distractor, and they were then slower to point to the target, when compared to the controls. This last mentioned result suggests that frontal lobe damage affected the ease of disengaging attention from a distractor, once it was selected. Soto et al. proposed that frontal patients had difficulty maintaining separate the template for the target from other information held in working memory. The patients were thus confused about whether they should respond to a selected item, even if it was a distractor.

Quite similar results to this, but based on the presence of new related distractors rather than the re-presentation of items from working memory, were reported by Belke et al. (2008). They had healthy participants hold a working memory load prior to searching for a target and examined the effects on search of presenting a related distractor in the search display (cf. Moores et al., 2003). Though effects on the initial saccades in search were unaffected by cognitive load, participants were delayed in responding due to the time taken to reject related distractors that were selected. To the extent that the working memory task made a demand on frontal lobe structures (Lavie \& De Fockert, 2006), these results point to the role of the frontal lobes in rejecting distractors once they are selected. This was tested more formally here, when we examined the effects of new, related distractors on search in frontal patients and age-matched controls. Following the results of Soto et al. (2006) we predicted that: (i) effects of the semantic distractor on the initial selection of stimuli should be unaffected by the lesion, and (ii) there should be impaired disengagement from a semantically related distractor, once selected. Thus the patients should not differ from age-matched controls on first fixation behavior, but reactions may be slower, fixation durations longer and more errors may arise when the patients make an orienting response to semantic distractors.

\section{Materials and methods}

\subsection{Participants}

The patient group comprised of nine right-handed patients with a range of lesions, but all including damage to the frontal cortex (see Fig. 1 and Table 1). There were four patients with unilateral right hemisphere damage (JQ, AS, TT and PW), and two with unilat- 
Lateral

Right lesion (shown on left)

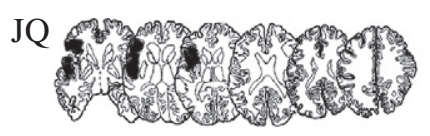

AS

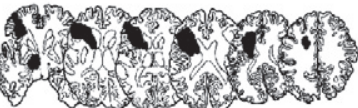

TT

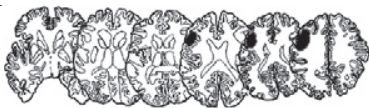

PW

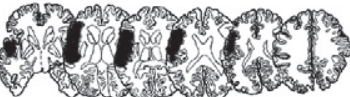

Left lesion (shown on left)

PH

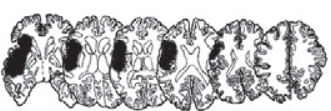

DS

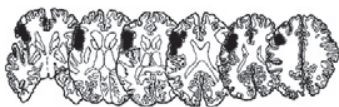

Medial and Bilateral

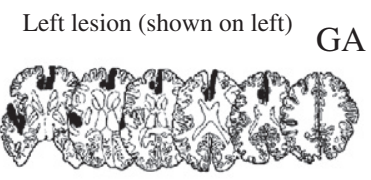

FK

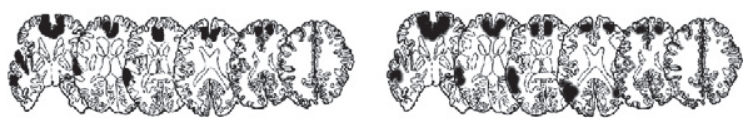

SP
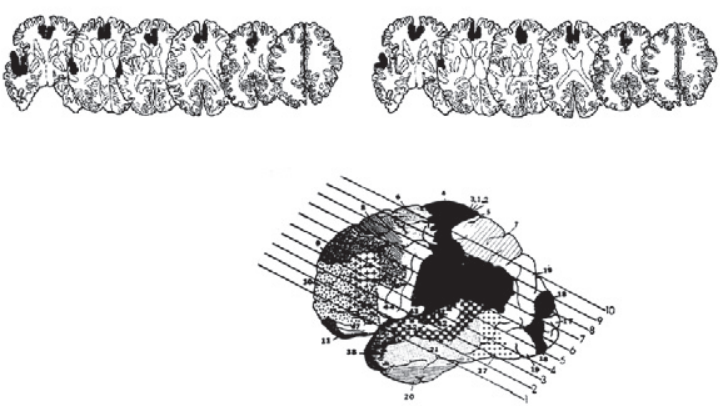

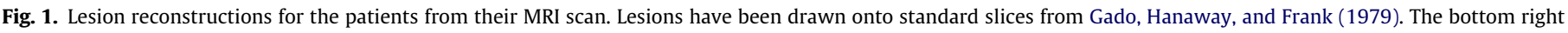
figure shows the 10 slices used. Only slices 3-8 are depicted here.

eral left hemisphere damage (PH and DS). ${ }^{1}$ In these cases, damage was to lateral areas of frontal cortex. There were also three patients with bilateral medial frontal damage (GA, FK and SP). In seven patients, the damage extended to and included the temporal lobes (the exceptions being DS and TT). The patients were between 32 and 73 years old (mean age 57, SD 15.2, all males). ${ }^{2}$ All patients had normal or corrected-to-normal vision. All patients gave their informed consent prior to taking part in the study.

The age-matched control group comprised of nine adults, matched according to the age of the patients tested (mean age 57, SD 16.6, two female). Two were postgraduate students from the University of Birmingham, who participated in return for pay-

\footnotetext{
1 There are several findings with frontal lobe patients (e.g., Thompson-Schill et al., 1998) which show that participants with left lateral lesions have particular problems in selecting appropriate responses from competing semantic alternatives. Unfortunately, due to the small numbers of patients in our unilateral left and right frontal sub-groups reliable comparisons could not be made. Nevertheless we note that any effects of semantic relatedness were inconsistent across the different measures we derived. For example, the left hemisphere patients did tend to show a stronger effect of relatedness than the right hemisphere patients on false alarms when targets were absent (a $5 \%$ increase in errors for left hemisphere patients compared with a $2 \%$ increase for right hemisphere patients, on related relative to unrelated trials). This is consistent with the left frontal region being required to select between semantically related items and with this process being impaired in the left hemisphere lesioned patients. On the other hand, the left hemisphere patients also showed increased first gazes to targets when a related distractor was present (an increase of $10 \%$ compared with the unrelated distractor baseline), while right hemisphere patients made fewer first gazes to targets in the related compared with the unrelated condition (a decrease of $8 \%$ ). This inconsistent pattern makes it unlikely that that the interference effects were carried by the left hemisphere patients. Indeed, our further sub-analysis indicated greatest disruption in patients with medial frontal lesions, not the left lateral lesions noted by Thompson-Schill et al. (see the Section 5).

${ }^{2}$ Age and visual search. The patients and age-matched controls were predominantly from the older adult age group, with two younger adults, creating a large age range overall. Effects of age on the relatedness effects were examined across different age groups in Telling (2009). The only significant difference in the effects of the related distractor across different age groups was that young adults showed a slightly greater effect of semantic relatedness on their error rates compared with older adults (effect size $1 \%$; $p=0.008$ )
}

ment in cash or course credits. These were both male and aged 28 and 33 years (approximating the ages of patients $\mathrm{PH}$ and FK). The remaining seven participants were older adults from the West Midlands, who volunteered and were paid for their time. These were aged between 51 and 73 (approximating the ages of the remaining patients GA, SP, JQ, TT, AS, DS and PW). All controls had reported themselves to be in good health, with no known neurological conditions. They were native British English speakers and were tested for 20/20 normal or corrected vision. The handedness of the participants was not recorded. All participants gave their informed consent prior to taking part in the study.

All of the patients either showed aspects of dysexecutive syndrome (e.g., scoring outside of the control range on the Brixton and Hayling tests of executive function, or performing poorly under dual task conditions (e.g., visual search with a memory load); see Table 1). There were three patients (GA, FK and SP) with a visual recognition problem that was apparent for animate but not for inanimate stimuli (note the scores for these patients for the Pyramids and Palm trees test of recognition; see also Humphreys and Forde (2005), Humphreys and Riddoch (2003), for studies of object recognition in these patients). However, only two target items were drawn from an animate category and both of these were stimuli that the patients had no difficulty in recognizing (bird and hand). The results should not be confounded by a categoryspecific recognition deficit.

\subsection{Stimuli}

The visual search display contained four objects, positioned at $12,3,6$ and 9 o'clock on the visual array and at a distance of $7.4^{\circ}$ of visual angle ( 170 pixels) from the midpoint of the screen. All pictures were selected from Snodgrass and Vanderwart (1980) and a picture gallery provided by the Max-Planck-Institute for Psycholinguistics, Nijmegen (NL). All stimuli were black and presented on a white background. The stimuli were 100 by 100 pixels, with a horizontal and vertical resolution of $72 \mathrm{dpi}$, corresponding to 4.6 by 
Table 1

Patient list, including lesion site and clinical details.

\begin{tabular}{|c|c|c|c|c|c|c|c|c|c|c|c|c|}
\hline Patient & $\begin{array}{l}\text { Sex/age/ } \\
\text { handedn. }\end{array}$ & $\begin{array}{l}\text { Years } \\
\text { post } \\
\text { lesion }\end{array}$ & $\begin{array}{l}\text { Main lesion } \\
\text { site - frontal }\end{array}$ & Etiology & Clinical deficit & $\begin{array}{l}\text { NART IQ } \\
\text { equiv. }^{\text {b }}\end{array}$ & $\begin{array}{l}\text { Brixton test } \\
\text { raw score }\end{array}$ & $\begin{array}{l}\text { Hayling } \\
\text { test }^{\mathrm{d}}\end{array}$ & $\begin{array}{l}\text { Pyramids } \\
\text { and palm } \\
\text { trees visual }^{\mathrm{a}}\end{array}$ & $\begin{array}{l}\text { Pyramids } \\
\text { and palm } \\
\text { trees } \\
\text { auditory }^{\mathrm{a}}\end{array}$ & $\begin{array}{l}\text { Corsi } \\
\text { blocks }\end{array}$ & $\begin{array}{l}\text { Digit span } \\
F(B)\end{array}$ \\
\hline JQ & $\mathrm{M} / 59 / \mathrm{R}$ & 3 & $\begin{array}{l}\text { Right frontal } \\
\text { and temporal }\end{array}$ & Stroke & $\begin{array}{l}\text { Elements of } \\
\text { dysexecutive } \\
\text { syndrome }\end{array}$ & 115 & 26 & 36 & 50 & 50 & 3 & $5(3)$ \\
\hline AS & $\mathrm{M} / 70 / \mathrm{R}$ & 4 & $\begin{array}{l}\text { Right middle } \\
\text { frontal gyrus } \\
\text { and medial } \\
\text { temporal cortex }\end{array}$ & Stroke & $\begin{array}{l}\text { Impaired sustained } \\
\text { attention, left } \\
\text { extinction, } \\
\text { and impaired } \\
\text { dual task performance }\end{array}$ & 102 & 26 & 28 & 50 & 50 & 5 & $6(4)$ \\
\hline TT & $\mathrm{M} / 67 / \mathrm{R}$ & 2 & $\begin{array}{l}\text { Right middle } \\
\text { frontal gyrus }\end{array}$ & Stroke & $\begin{array}{l}\text { Impaired working } \\
\text { memory and dual } \\
\text { task performance }\end{array}$ & 110 & 21 & 32 & 51 & 51 & 4 & $5(3)$ \\
\hline PW & $\mathrm{M} / 73 / \mathrm{R}$ & 5 & $\begin{array}{l}\text { Right inferior } \\
\text { and middle } \\
\text { frontal gyri, } \\
\text { right superior } \\
\text { temporal gyrus }\end{array}$ & Stroke & $\begin{array}{l}\text { Aspects of } \\
\text { dysexecutive } \\
\text { syndrome }\end{array}$ & 105 & 27 & 60 & 50 & 49 & 3 & $5(3)$ \\
\hline PH & $\mathrm{M} / 32 / \mathrm{R}$ & 5 & $\begin{array}{l}\text { Left medial } \\
\text { and superior } \\
\text { temporal, } \\
\text { left inferior } \\
\text { and middle } \\
\text { frontal gyri }\end{array}$ & Stroke & $\begin{array}{l}\text { Non-fluent aphasia, } \\
\text { deep dyslexia, } \\
\text { impaired verbal } \\
\text { short term memory } \\
\text { and dual task } \\
\text { performance }\end{array}$ & 80 & 21 & 34 & 49 & 50 & 2 & $2(0)$ \\
\hline DS & $\mathrm{M} / 72 / \mathrm{R}$ & 14 & $\begin{array}{l}\text { Left inferior, } \\
\text { middle and } \\
\text { superior } \\
\text { frontal gyri }\end{array}$ & Stoke & $\begin{array}{l}\text { Non-fluent aphasia, } \\
\text { impaired verbal short } \\
\text { term memory, aspects } \\
\text { of dysexecutive } \\
\text { syndrome }\end{array}$ & 105 & 20 & 54 & 48 & 48 & 3 & $4(4)$ \\
\hline GA & $\mathrm{M} / 51 / \mathrm{R}$ & 12 & $\begin{array}{l}\text { Bilateral medial } \\
\text { and anterior } \\
\text { temporal lobes } \\
\text { extending into } \\
\text { left medial } \\
\text { frontal region }\end{array}$ & $\begin{array}{l}\text { Herpes } \\
\text { simplex } \\
\text { enceph. }\end{array}$ & $\begin{array}{l}\text { Aphasia, amnesia, } \\
\text { category-specific } \\
\text { recognition disorder, } \\
\text { aspects of dysexecutive } \\
\text { syndrome }^{\text {a }}\end{array}$ & 102 & 20 & 66 & 40 & 41 & 4 & $6(2)$ \\
\hline FK & $\mathrm{M} / 37 / \mathrm{R}$ & 12 & $\begin{array}{l}\text { Bilateral, superior } \\
\text { and medial frontal } \\
\text { regions; bilateral } \\
\text { superior and medial } \\
\text { temporal gyri, } \\
\text { bilateral } \\
\text { lateral occipital gyri }\end{array}$ & Anoxia & $\begin{array}{l}\text { Category-specific } \\
\text { recognition disorder; } \\
\text { dysexecutive }_{\text {syndrome }^{\mathrm{a}}}\end{array}$ & 112 & 38 & 72 & 36 & 37 & 4 & $5(4)$ \\
\hline SP & $\mathrm{M} / 52 / \mathrm{R}$ & 11 & $\begin{array}{l}\text { Bilateral damage to } \\
\text { middle and anterior } \\
\text { temporal regions } \\
\text { extending into the } \\
\text { frontal lobes }\end{array}$ & $\begin{array}{l}\text { Herpes } \\
\text { simplex } \\
\text { enceph. }\end{array}$ & $\begin{array}{l}\text { Amnesia, } \\
\text { category-specific } \\
\text { recognition disorder, } \\
\text { aspects of } \\
\text { dysexecutive } \\
\text { syndrome }^{\mathrm{a}}\end{array}$ & 110 & 20 & 48 & 42 & 40 & 5 & $8(5)$ \\
\hline
\end{tabular}

a FK, GA and SP all had some problems with Pyramids and Palm Trees (Howard \& Patterson, 1992), a test of semantic access from words and pictures - and thus some recognition difficulties.

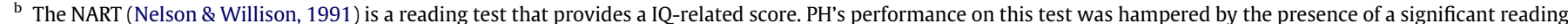

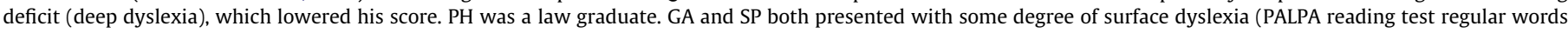
both 30/30, irregular words 24 and 25/30 respectively). No other patients had any reading difficulty.

c The Brixton test of executive function (Burgess \& Shallice, 1997) provides a measure of non-verbal executive function. A raw score above 26 indicates a clinical abnormality.

d The Hayling test (Burgess \& Shallice, 1997) provides a measure of verbal executive function. The data show converted scores. A score above 18 is abnormal.

$4.6^{\circ}$ of visual angle when viewed $60 \mathrm{~cm}$ from the monitor. Randomization software was used to create the visual search arrays (StimulusGenerator, ( ) D.G. Watson), with objects being randomly assigned to a screen quadrant.

Participants were presented with a target word, e.g., bird, followed by a four-object search array. Each of the four objects was taken from a set of 16 items, 64 in total: a target set, a semanticcompetitor set, a semantic-associate set and an unrelated filler set (see Appendix). Competitors were drawn from the same-category as the target. Synonyms or antonyms were not included. Associates held either a "part-whole" (e.g., feather-bird) or "toolobject" (e.g., bow-arrow) relationship with the target. The items were the same as those used by Belke et al. (2008). The pictures were chosen to minimize visual similarity between the stimuli and previous ratings with this set of items showed no differences in visual similarity between related and unrelated pairs (Belke et al., 2008).

Belke et al. (2008) assessed the associative strength of the target-distractor pairs in the word-association norms available in the Edinburgh Association Thesaurus (http://www.eat.rl.ac.uk/; Kiss, Armstrong, Milroy, \& Piper, 1973), which lists the words (adjectives, nouns and verbs) given as responses to a target in a word-association task. On average, the names of associative distractors were mentioned significantly more often in response to the target words we used in our experiment (23\%) compared with the names of the same-category competitors $(3.2 \% ; t(15)=3.37$, 
$p=.004)$. These normative data are listed in the Appendix. These items extend the stimuli used by Moores et al. (2003) by enabling us to examine the effect of categorically-related as well as associatively-related distractors. Experiments using word production and word perception tasks have reported differing effects between the two forms of distractor (e.g., Alario, Segui, \& Ferrand, 2000; Perea \& Rosa, 2002; Wheeldon \& Monsell, 1994). However, Belke et al. (2008) reported that interference was equally strong between associates and semantic-competitors, indicating that item-type did not modulate effects on visual attention here.

In each block, half of the trials were target-present and the remaining trials were target-absent (where the target was replaced by a foil randomly chosen from the target set). Two thirds of the trials had a semantically related distractor present (in addition to the target or foil). For half of these trials, related distractors were semantically associated to the target (e.g., feather for the target bird) and for the other half, the distractors were categorically-related competitors to the target (e.g., fish). In the remaining third of trials, no related distractors were present. In this case, the related associate or competitor was replaced by an unrelated member of the associate or competitor set (foil). For example, Fig. 2a shows a target-present, related distractor trial, with a member of the competitor set related to the target probe ( fish), a member of the associate set unrelated to the target probe (propeller), the target (bird) and an additional filler object, which was semantically and phonologically unrelated to the remaining objects in the display (pear). Thus, each search display featured a member of the target set, a member of the associate set, a member of the competitor set and a member of the filler set.

Preliminary analyzes of the data indicated that there were no differences between associate and competitor distractors, nor were there differences between part-whole and tool-object associations.
This matches the data reported by Belke et al. (2008). Hence these differences are not highlighted and we use the term semantically related distractors to refer to all types of semantic relation. There were thus four primary conditions, as shown in Fig. 2b, with the withinsubjects factors of target status (present or absent) and distractor condition (semantically related and semantically unrelated).

One search array was produced per item, per condition, per block. There were 96 trials per block and four blocks in total (384 trials). Participants were exposed to each object four times per condition. Two different orientations of the object were used so that searching was not based on specific local features. Half of all stimuli in each block were in one orientation and half in the opposite orientation. In the target-present condition, the search target was always shown in the same orientation as corresponding object in the search display. The experimental conditions were presented in a mixed order across participants.

\subsection{Apparatus}

The experiment was controlled using a Pentium IV (1.5 GHz) PC. The stimuli were displayed on a Triniton Multiscan G240 monitor $\left(17^{\prime \prime}\right)$, with a screen resolution of 600 by 800 pixels. Eye movement data were processed using an Eyelink SensoriMotoric Instruments (SMI) v 2.04 head mounted eye-tracker from SR Research Limited.

\subsection{Procedure for control participants}

The control participants familiarized themselves with a picture booklet, containing pictures with names written beneath them for all stimuli used in the experiment. The participants assumed a suitable viewing position from the monitor (typically $60 \mathrm{~cm}$ ) in the laboratory, which was dimly lit for the duration of the experiment.

a

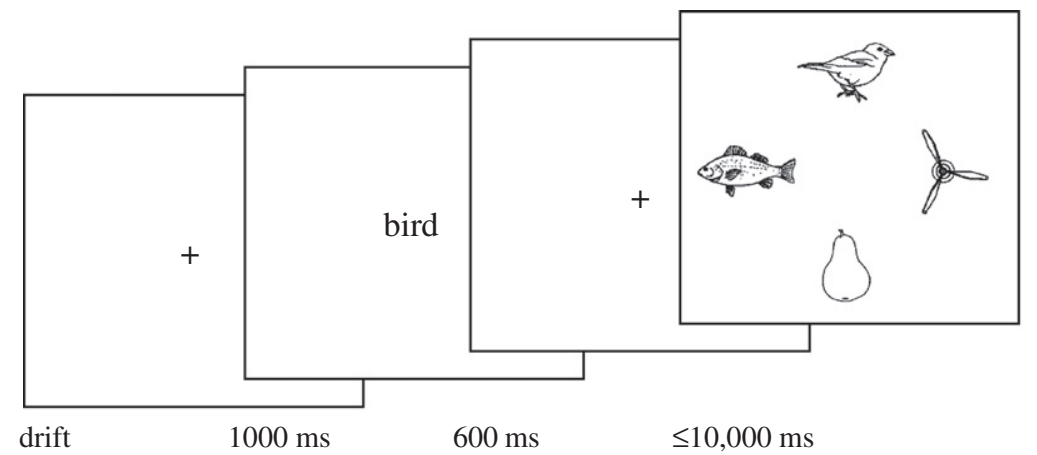

b

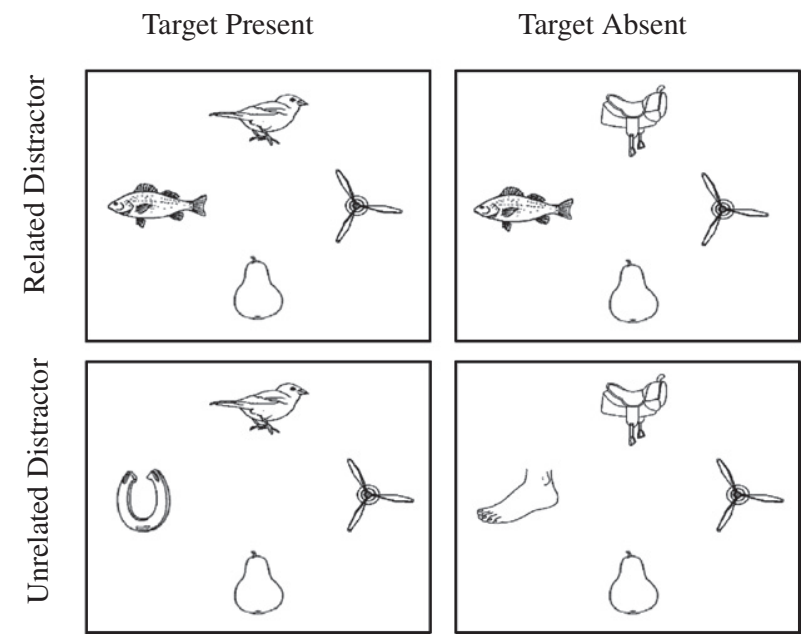

Fig. 2. (a) An example trial sequence. (b) Example displays in each condition. 
The eye-tracker was positioned on the participant's head, camera aligned so that one eye was in focus and the system calibrated. Eye position data were gathered from the right eye.

Each trial began with a fixation cross at the center of the screen. Participants were asked to look at the cross so that drift correction could be made, correcting for any change in head position during the previous trial. The participants managed drift correction themselves by pressing a button on their hand-held control pad whilst looking at the fixation point. Immediately after drift correction, the target word was presented in the center of the screen for $1000 \mathrm{~ms}$ (e.g., "bird") followed by a fixation cross for $600 \mathrm{~ms}$. Next, the search display was presented until the participant responded, for a maximum duration of $10 \mathrm{~s}$. Participants were asked to search for the target picture amongst the four pictures on the screen (see Fig. 2a). They were instructed to respond by pressing the left green button of a hand-held control pad when the target was present and the right red button when the target was absent. Upon pressing the button, the next fixation point appeared (drift) indicating the start of a new trial. The total time to run the experiment was $60 \mathrm{~min}$, including $15 \mathrm{~min}$ for instruction and calibration and $45 \mathrm{~min}$ of testing (with breaks and optional removal of headset in between blocks included). Following completion of all tasks, participants were verbally debriefed.

\subsection{Procedure for patients}

The experimental procedure for the patient group was identical to that of the age-matched control group, except for the following additions: (i) Prior to the experiment, the experimenter explained the task verbally. The patients were also asked to name each of the pictures in the picture booklet, which had the names written beneath. Any incorrect names were corrected verbally by the experimenter so that the patient was aware of the correct name for that picture. The opportunity to re-name any picture was offered, if the patient wanted to double-check any of the names. (ii) The experimenter managed the patient's drift control. (iii) The hand-held control pad was responded to using the left and right colored buttons. Whereas most participants responded with a one finger from their left and one from their right hand, PW responded using his active hand only, due to hemiparesis. (iv) The patients carried out blocks within testing sessions of up to $1 \mathrm{~h}$. Four blocks of data were gathered for each patient over a number of sessions. (v) To assess whether the patients could recognize the stimuli, they were shown all target-distractor pairs of pictures used in the visual search experiment and were asked to point at the target picture. The distractors were either related (semantic competitor or associate) or unrelated to the target picture. No time limit was given. The pairs were presented in a randomized order. This recognition test was carried out after the main experiment. All of the patients pointed to the target on at least $94 \%$ of the trials (a further breakdown of this finding is provided in the Section 5). Critically, the patients who showed some evidence of impaired recognition for living things could identify all of the target objects used in the experiment.

\subsection{Analyses}

The first five trials of the first block were considered as practice and excluded from the data set. Incorrect responses accounted for a further $3 \%$ of control group and $15 \%$ of patient responses. Outlying RTs were removed by eliminating those responses that were beyond three standard deviations from a participant's mean (1\% in controls; $1 \%$ in patients). A further reduction to the behavioral data set was made by coding any instances at display onset where eye gaze did not land in an area $2^{\circ}$ of visual angle around the centre of the screen (drift errors, $5 \%$ in controls; $17 \%$ in patients). This excluded trials where the participant's gaze was inclined towards one quadrant more than another because of the off-center starting point. Correct responses only were selected and used as a basis for RT analysis and eye data preparation (90\% controls; $70 \%$ patients).

Eye movement data were selected from correct trials only. The mean saccade duration (i.e., duration between offset from current fixation to onset of next fixation) was calculated for each group: On average, the saccades made by the age-matched controls lasted for $45 \mathrm{~ms}$ and those for the patients lasted for $59 \mathrm{~ms}$. Gaze durations were calculated to include multiple fixations to the same object. Trials were excluded when the first gaze made to the middle region occurred $150 \mathrm{~ms}$ after trial onset (e.g., due to blinking so that eyes were not at the middle point when the trial started). The remaining trials were those that were initiated following a gaze to the middle region. Trials where no eye movements were made away from the middle region before making a response were coded and subsequently removed from the eye movement analyses, but not for the behavioral analysis. This affected $6 \%$ of the trials for the controls and $3 \%$ of the trials for the patients.

The time taken by participants to move their gaze from the middle region to one of the objects was analyzed along with the proportion and duration of first gazes to the target, associate, competitor and unrelated fillers. The first gaze data comprised the proportion of first gazes made away from the middle region after trial onset to one of the four objects. On target-absent trials, first gazes to the foil were studied and on semantically unrelated trials, first gazes to the unrelated filler object were studied.

A split-plot ANOVA was conducted across participants with a between-subjects factor of group (age-matched controls versus patients) and within-subjects factors of target status (target-absent versus target-present) and distractor condition (related, based on averaging of associate and competitor distractor present conditions, versus unrelated, where no related distractor was present).

\section{Results}

\subsection{Behavioral results}

\subsubsection{Error rates}

Analyses of variance showed that the patients made more errors than the controls (14\% versus 3\%: $F(1,16)=33.5, p<0.001$, $\left.\eta^{2}=0.68\right)$. There were generally more errors during target-present than absent trials, although this failed to reach significance $(11 \%$ versus $\left.7 \%: F(1,16)=4.2, p=0.056, \eta^{2}=0.21\right)$. There was no effect of distractor condition $\left(F(1,16)=1.9, \quad p=0.186, \eta^{2}=0.11\right)$. A 3-way interaction between target status, distractor condition and group approached significance $\left(F(1,16)=4.3, p=0.056, \eta^{2}=0.21\right)$. Fig. $3 b$ shows a difference between the errors for the controls and patients, with patients making more errors on target-absent trials when a related distractor was present compared with when the distractor was unrelated to the target. Separate analyses of variance were performed on target-present trials and target-absent trials. On target-present trials there was a significant effect of group only $\left(F(1,16)=29.14, p<0.001, \eta^{2}=0.65\right)$. On target-absent trials there were main effects of group $\left(F(1,16)=11.66, p=0.004, \eta^{2}=0.42\right)$ and distractor condition $\left(F(1,16)=5.30, p=.035, \eta^{2}=0.25\right)$, and an interaction between the two factors $(F(1,16)=7.11, p=0.017$, $\left.\eta^{2}=0.31\right)$. The patient group alone showed a main effect of distractor condition (patients: $t(8)=2.53, p=0.035, \eta^{2}=0.45$; controls: $\left.t(8)=0.94, p=0.376, \eta^{2}=0.09\right)$, with more errors on target-absent related trials (16\%) than on target-absent unrelated (9\%) trials.

\subsubsection{Reaction times for correct responses}

Analyses of variance showed that the patient group responded more slowly than the controls $(2440$ ms versus $986 \mathrm{~ms}: F(1,16)=$ 

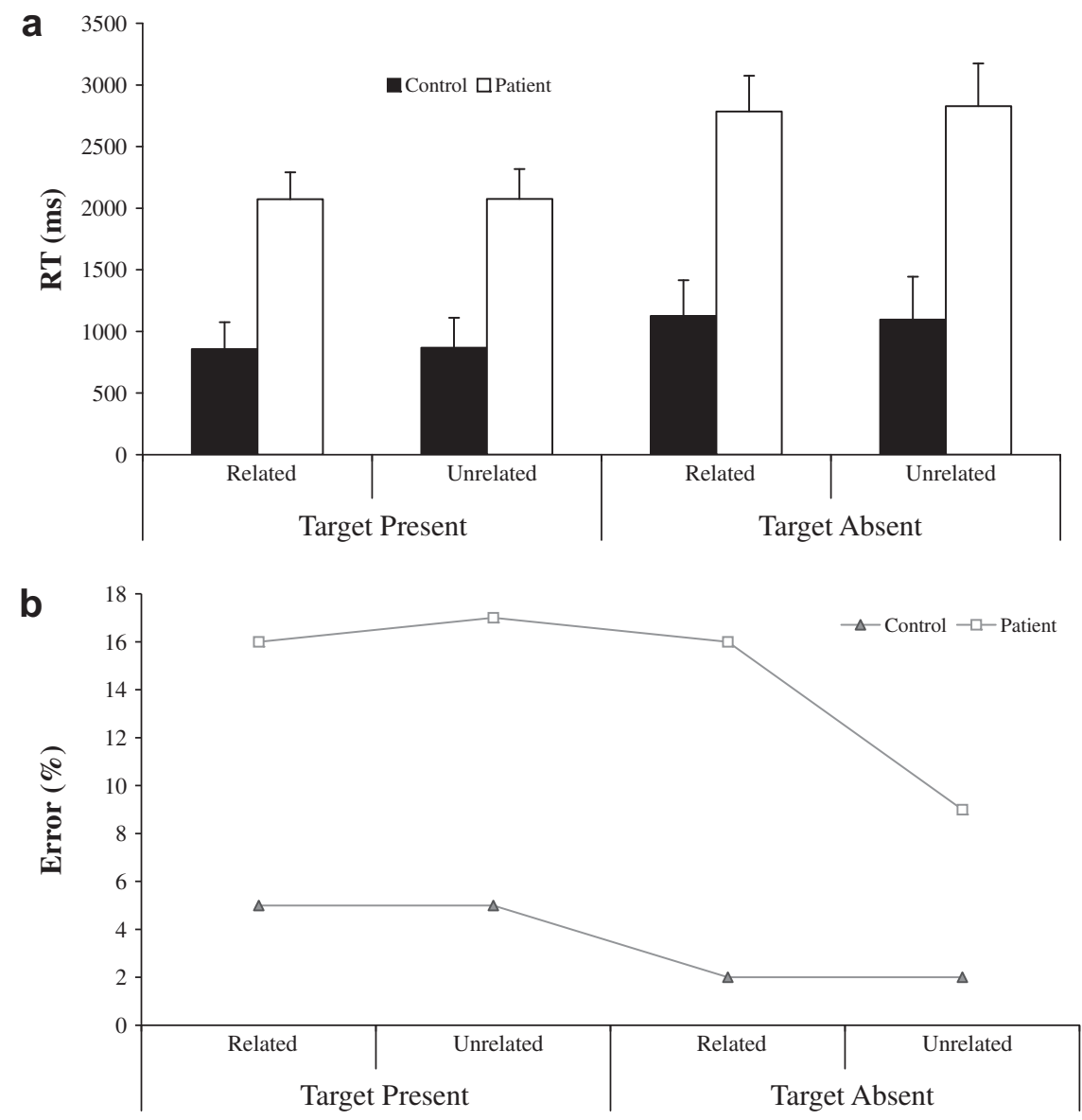

Fig. 3. Mean correct RTs (in ms, (a)) and percentage errors (b) for patients and controls.

14.47, $\left.p=0.002, \eta^{2}=0.47\right)$. Reactions were slower on target-absent than target-present trials overall (1958 ms versus $1468 \mathrm{~ms}$ : $\left.F(1,16)=31.58, p<0.001, \eta^{2}=0.66\right)$. The distractor condition had no reliable effects. There were no interactions.

\subsubsection{RTs for incorrect responses}

The incorrect responses for the patients were also analyzed. Analyses of variance found a significant difference between incorrect responses when related distractors were present than when absent ( 3323 ms versus $2976 \mathrm{~ms}: F(1,8)=8.73, p=0.018, \eta^{2}=0.52$ ). There were no other effects.

\subsection{Eye movements}

Comparisons of the eye movement data for patients and controls on correct trials are summarized below. In addition, eye movements made by the patients on incorrect response trials were also analyzed (too few errors were made by the controls for their data to be analyzed). Only first gaze durations to the distractor yielded significant main effects, and these are reported below.

\subsection{Correct response trials}

\subsubsection{Offset of gaze from middle region}

Analyses of variance showed that there was a trend for longer gazes to the middle region on target-absent ( $255 \mathrm{~ms}$ ) compared to present trials $\left(245 \mathrm{~ms} ; F(1,16)=4.21, p=0.057, \eta^{2}=0.21\right)$. There was one interaction between group and distractor condition $\left(F(1,16)=7.81, p=0.013, \eta^{2}=0.33\right)$. The data were analyzed sepa- rately for each group using paired comparisons. Only the control group showed a main effect of distractor condition, with shorter offset times on trials where there was a related distractor (246 ms) compared with trials with unrelated distractors $(254 \mathrm{~ms} ; t(8)=$ $3.39, p=0.009, \eta^{2}=0.59$ ). There was no effect of distractor condition for the patients $\left(t(8)=1.57, p=0.154, \eta^{2}=0.24\right.$; see Fig. 4$)$. These data suggest that the controls were more sensitive to the presence of a related distractor prior to the onset of a saccade than the patients.

\subsection{Proportion of first gazes to the target}

Analyses of variance showed that the controls made more first gazes to the target than the patients ( $57 \%$ versus $35 \%$ : $F(1,16)=$ 22.67, $p<0.001, \eta^{2}=0.59$ ). There were no significant differences between the other variables (see Fig. 5b).

\subsubsection{Proportion of first gazes to distractors}

The patients made more first gazes to distractors than the controls, averaged across distractor type (26\% versus $24 \%$ : $F(1,16)=$ 5.66, $p=0.030, \eta^{2}=0.26$ ). Across the groups there were more first gazes to the distractor on target-absent than present trials $(29 \%$ versus 20\%: $F(1,16)=59.48, p<0.001, \eta^{2}=0.79$ ), and more first gazes to distractors when they were semantically related to the target compared with when they were unrelated (27\% versus $22 \%$ $\left.F(1,16)=14.94, p=0.001, \eta^{2}=0.48\right)$. There was a significant interaction between target status and group $(F(1,16)=11.83, p=0.003$, $\eta^{2}=0.43$ ). This was broken down by assessing the data separately for target-present and absent trials, averaging across distractor 


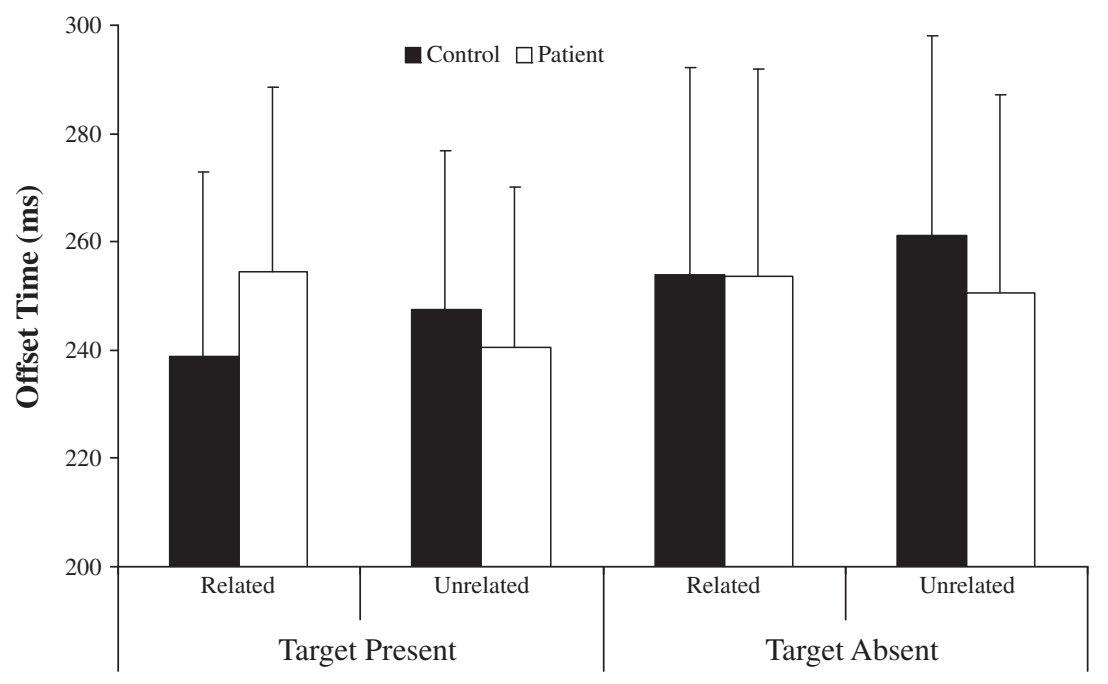

Fig. 4. Mean times to offset gaze from central region for patients and controls (correct response trials only).
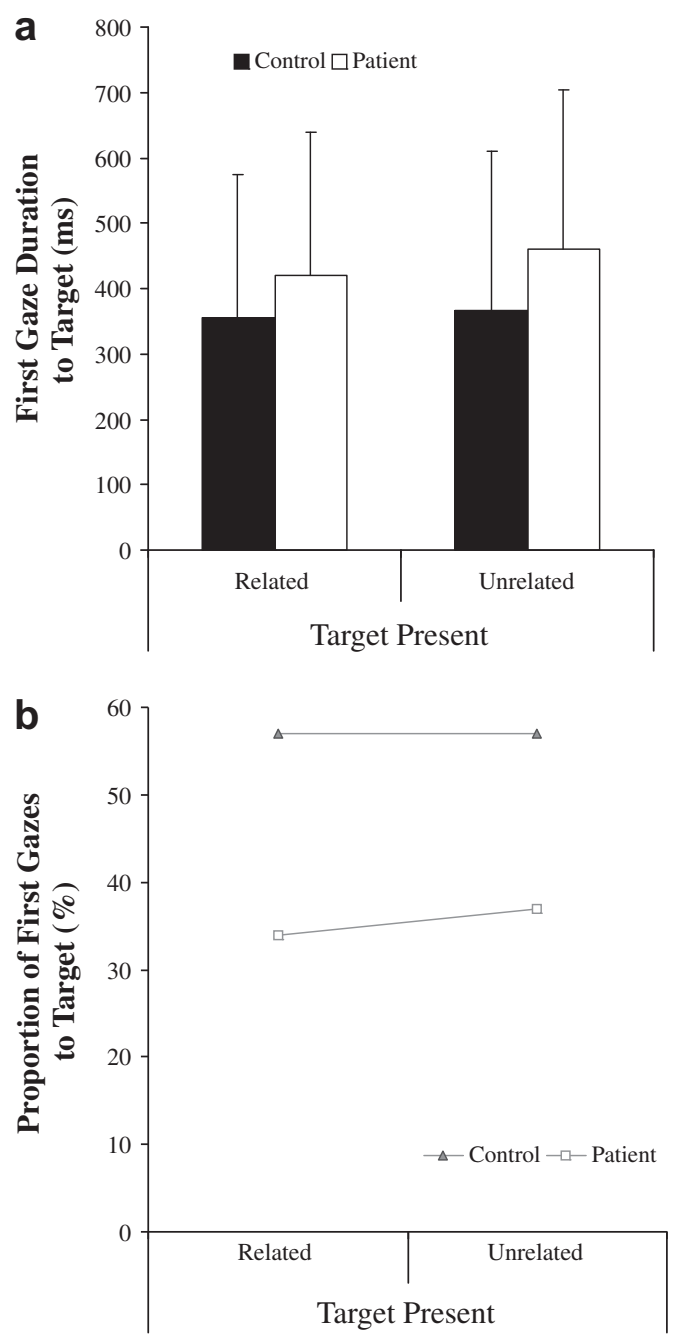

Fig. 5. Duration of the first gaze at the target (a), along with the proportion of first gazes made to the target (b), for patients and controls (correct response trials only).

type. Only target-present trials showed a main effect of group, with patients looking to distractors more frequently than the controls (23\% versus $17 \%$ : $F(1,16)=15.13, p=0.001, \eta^{2}=0.49$; target-ab- sent $28 \%$ (patients) versus $31 \%$ (controls); $F(1,16)=3.14, p=.095$, $\eta^{2}=0.16$ ). On target-absent trials there was no difference between the groups in the effect of the distractor condition on first fixations (see Fig. 6b).

\subsubsection{First gaze duration to the target}

Analyses of variance revealed a main effect of distractor condition only, with shorter gazes to the target in the presence of a related than unrelated distractor ( $388 \mathrm{~ms}$ versus $413 \mathrm{~ms}, F(1,16)=6.23$, $p=0.024, \eta^{2}=0.28$ ). There were no interactions (see Fig. 5a).

\subsubsection{First gaze duration to distractors}

The patients gazed at distractors for longer than the controls ( $231 \mathrm{~ms}$ versus $158 \mathrm{~ms}: F(1,16)=21.17, p<0.001, \eta^{2}=0.57$ ). Across the groups gazes were longer on target-absent than on target-present trials (209 ms versus $179 \mathrm{~ms}: F(1,16)=8.20, p=0.011$, $\left.\eta^{2}=0.34\right)$, and on trials when there was a semantically related rather than an unrelated distractor $(204 \mathrm{~ms}$ versus $184 \mathrm{~ms}: F(1,16)=9.07$, $\left.p=0.008, \eta^{2}=0.36\right)$. Significant interactions occurred between target status and distractor condition $(F(1,16)=4.72, p=0.045$, $\left.\eta^{2}=0.23\right)$ and between target status, distractor and group $\left(F(1,16)=4.52, p=0.049, \eta^{2}=0.22\right)$.

The two-way interaction was broken down by analyzing the data for target-present and target-absent trials averaged across groups. For target-present trials only there was a reliable main effect of distractor condition, with longer gazes to semantically related rather than unrelated distractors (196 ms versus $162 \mathrm{~ms}$ : $\left.F(1,16)=10.60, p=0.005, \eta^{2}=0.38\right)$. There was no effect of distractor condition on target-absent trials $(213 \mathrm{~ms}$ versus $205 \mathrm{~ms}$ : $F(1,16)=0.76)$.

The three-way interaction was broken down by analyzing the data for each group separately. For the control group there was a reliable main effect of target status only, with longer gaze durations to distractors on target-absent than present trials (182 ms versus $\left.133 \mathrm{~ms}: F(1,8)=17.54, p=0.003, \eta^{2}=0.69\right)$. There was no effect of distractor type and no interaction between distractor condition and target status. For the patient group there was no effect of target status $\left(F(1,8)=0.35, p=0.572, \eta^{2}=0.04\right)$, but a main effect of distractor condition, with longer gazes to the related distractor than to unrelated distractors $(244 \mathrm{~ms}$ versus $217 \mathrm{~ms}: F(1,8)=$ 8.64, $p=0.019, \eta^{2}=0.52$ ). There was also an interaction between target status and distractor $\left(F(1,8)=8.04, p=0.022, \eta^{2}=0.50\right)$. There was a significant effect of distractor for target-present trials 
a

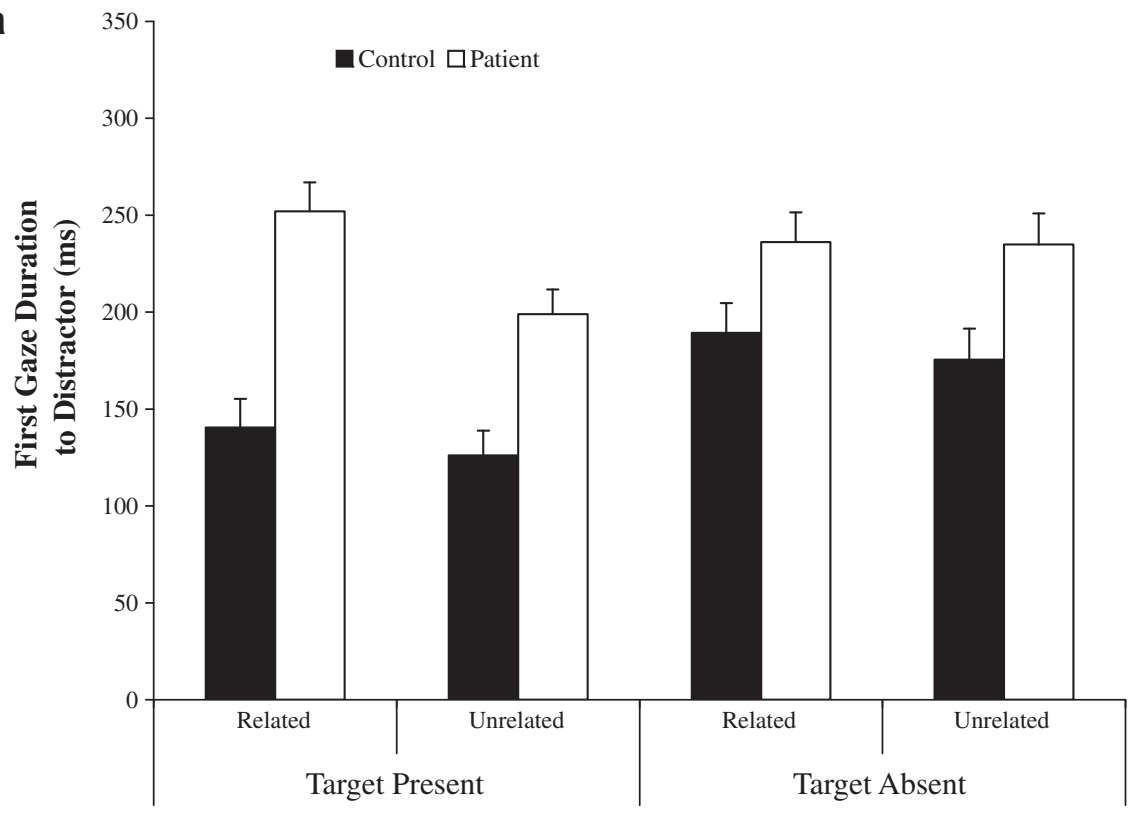

b

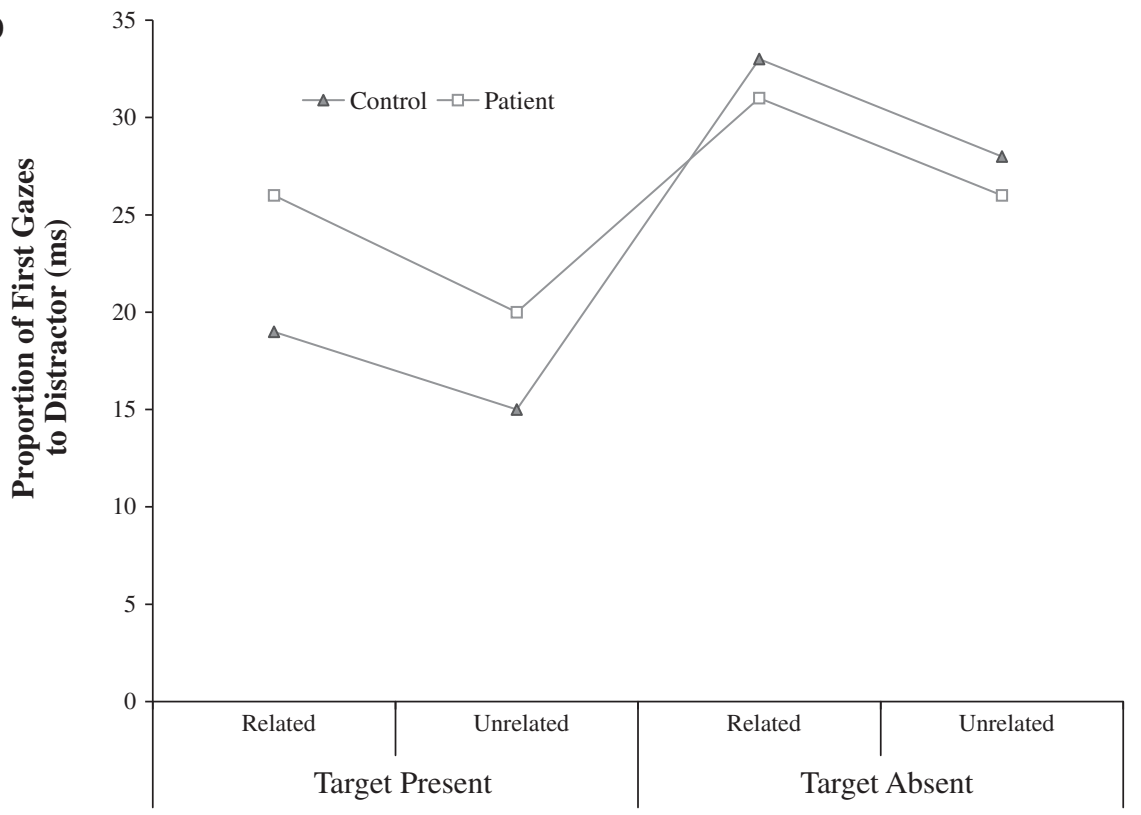

Fig. 6. Mean first gaze durations to distractors (a) and mean proportions of first gazes to the distractors (b) for patients and controls (correct response trials only).

only (target-present: $t(8)=3.85, p=0.005, \eta^{2}=0.65$; target-absent: $t(8)=0.1, p=0.924, \eta^{2}<0.01$; see Fig. 6a)

\subsubsection{Incorrect response trials}

4.4.4.1. First gaze duration to the distractor. The patients gazed longer at distractors (whether semantically related or unrelated to the target) on target-present, than target-absent trials (374 versus $267 \mathrm{~ms}: F(1,8)=8.43, p=0.020, \eta^{2}=0.52$ ). Gaze durations were also longer on distractors that were semantically related to targets than on semantically unrelated distractors ( 369 ms versus $272 \mathrm{~ms}$ : $\left.F(1,8)=5.02, p=0.055, \eta^{2}=0.39\right)$. The interaction between these two factors was not reliable $\left(F(1,8)=2.31, p=0.167, \eta^{2}=0.22\right)$, although there was a trend towards longer lasting gazes to the semantic distractors on target-absent relative to present trials (target-present: 283 versus $251 \mathrm{~ms}$ on related and unrelated distractors; target-absent: 455 versus $292 \mathrm{~ms}$, respectively).

\section{Discussion}

5.1. The frontal patients as a group performed differently from the agematched controls in the following ways

(a) The patients made more false positive errors on related than on unrelated trials.

(b) The patients' time to offset the gaze from the central fixation point was less affected by distractor type than the controls', i.e., only the controls showed faster offsets of fixation when a related distractor rather than an unrelated distractor was present.

(c) The patients made fewer first gazes to the target than the controls. This was unaffected by distractor type.

(d) The patients made more first gazes to distractors (regardless of the distractor condition), particularly on target-present trials. 
(e) The patients made longer lasting first gazes to related relative to unrelated distractors, particularly on target-present trials.

(f) In addition, the patients' incorrect responses took longer on related relative to unrelated trials; in control participants, incorrect responses were too infrequent for analysis.

(g) On incorrect response trials, the patients made longer lasting first gazes to related relative to unrelated distractors, particularly on target-absent trials.

Visual search for complex stimuli such as line drawings of objects likely involves at least two stages: first, initial selection of an item for an orienting response (required to verify the target) and, after this, a target verification process (matching a detailed re-presentation of the selected stimulus to a target template (see Duncan \& Humphreys, 1989). The data for frontal patients reported here can be accounted for in terms of the patients having two deficits compared with the controls. First, there is evidence for a deficit in the initial selection of the target. This is indexed by several findings including the reduced effect of semantically related distractors on the time to offset fixation, the reduced number of first gazes to the target, and the increased number of first gazes to distractors. In each case the data suggest that the patients were less able to use peripheral visual information to guide search. This meant that the times to offset fixation were more strongly influenced by related distractors in controls than in patients. Second, there is evidence that the patients' verification stage was disrupted following the selection of an item to saccade to. This verification process was affected by whether or not the distractor was related to the target. The patients were prone to making an error by responding to the distractor (on target-absent trials), their responses were slower on incorrect trials when a related distractor relative to unrelated distractor was present, and the patients showed longer gaze durations than controls when distractors were semantically related to targets. These longer gaze durations on related distractors also occurred on error trials. These problems in verifying whether a target was present, after orienting to the related distractor, were most evident on target-absent rather than target-present trials because, on target-present trials, a response to the related distractor would be classed as correct.

These results provide a partial fit with the data reported by Soto et al. (2006) who found that patients with frontal lobe damage were strongly affected once they attended to a distractor matching an item held in working memory: Patients made more errors and were slower to respond than the control group. However, the patients did not differ from the controls in terms of effects of the re-appearance of the working memory stimulus on the proportions of first fixations made to distractors. That is, there was no evidence for abnormally strong top-down guidance on the first stage of selection, but there was a problem in rejecting related distractors once they were selected. Like Soto et al. (2006), we too found that there was an impairment in rejecting related distractors after they had been selected (indicated by increased errors on target-absent trials and long gaze durations to related distractors). This is consistent with frontal cortex being important for keeping separate representations of the target from other activated re-presentations (e.g., of related stimuli). Soto et al., however, reported no differential effects of frontal lobe damage on the first stage of selection. In contrast to this, our data point to the frontal patients also being impaired at this first stage, with their search being less guided by the target and fixation offsets being less influenced by peripheral, related distractors. One reason for this contrast may be the complexity of the stimuli. We used relatively complex line drawings of everyday objects, whereas Soto et al. used simple 2D colored shapes. The patients may remain able to guide the first stage of search with relatively simple stimuli, but show a deficit in the first stage of selection with more complex stimuli. In addition, in our study the target and distractor could be semantically related whereas targets and distractors were unrelated in Soto et al.. This additional degree of relatedness could have exacerbated the problems the patients had in rejecting a distractor after it had been selected.

\subsection{Patient sub-groups}

Although we have presented the frontal patients as a single group, it should be borne in mind that the patients had a diverse set of lesions. While the majority of the patients had relatively lateral lesions affecting ventrolateral or dorsolateral prefrontal regions (the lateral group, Fig. 1 and Table 1), three patients (SP, FK and GA) had damage to the anterior cingulate plus also damage to anterior temporal regions (the AC/AT group). An analysis of these sub-groups of patients indicated that the patients with AC/AT damage were particularly affected by the related distractor. This difference was most pronounced for the error data, with the AC/AT patients being particularly prone to making false positive responses to related distractors on target-absent trials.

A further analysis of errors on target-absent trials revealed an interaction between the distractor condition and patient subgroup $\left(F(1,7)=7.14, p=0.032, \eta^{2}=0.51\right)$. While the lateral subgroup also showed an effect of related distractors on errors when compared to controls (a difference in error rate with related versus unrelated distractors of $3 \%$, compared with a difference of $-0.5 \%$ for the controls: $\left.F(1,13)=7.30, p=0.018, \eta^{2}=0.36\right)$, this effect was particularly large for the AC/AT sub-group (a difference of $15 \%$ in the error rate; $F(1,10)=22.80, p=0.001, \eta^{2}=0.70$ ) (see Table 2). This fits with the arguments that the AC is involved in error monitoring (Blasi et al., 2006; Carter et al., 1998). The data suggest that patients with AC/AT damage have difficulty in refraining from responding to a related stimulus that they have oriented to.

It is also the case that the AC/AT patients all showed difficulties with the Pyramids and Palm Trees standardized test (Howard \& Patterson, 1992) indicating some difficulty in object recognition. A comparison of the mean scores for the two patient sub-groups on the clinical test scores reported in Table 1 yielded no significant performance difference, except for the Pyramids and Palm Trees visual and auditory scores (auditory: 10 point difference, $t(7)=10.33$, $p<0.001$; visual: 10 point difference, $t(7)=7.89, p<0.001$ ). However, difficulty in recognition per se, cannot provide a full explanation of our results. For example, the AC/AT patients made no more errors than the other frontal patients in our pre-experimental test of recognition for the objects used $(t(7)=-0.921, p=0.388)$. There was also no correlation between errors on the pre-experimental test and the magnitude of the effects of related distractors on errors ( $n=9, r=-0.56, p=0.114)$. We also used only two animate targets (bird and hand), which the patients could identify, so a problem due to their category-specific recognition problem for animate objects can be discounted. We conclude that, at least with the present items, poor object recognition was not the key factor.

Were there effects of distractor relatedness on the first stage of selection in the AC/AT patients? For the proportion of first saccades

Table 2

Mean error rates (\%) for the two lesion groups and the control group, with standard deviations in parentheses.

\begin{tabular}{llrrl}
\hline Target status & Distractor & \multicolumn{1}{c}{ AC/AT } & Lateral & Controls \\
\hline Target-present & Related & $21(4)$ & $15(6)$ & $5(2)$ \\
& Unrelated & $17(0)$ & $17(12)$ & $5(3)$ \\
Target-absent & Related & $28(17)$ & $9(2)$ & $2(1)$ \\
& Unrelated & $13(8)$ & $6(2)$ & $2(2)$ \\
\hline
\end{tabular}


Table 3

Mean proportions (standard deviations in parentheses) of first gazes to the distractor (\%) in each condition for the two lesion groups and the control group.

\begin{tabular}{lllll}
\hline Target status & Distractor & AC/AT & Lateral & Controls \\
\hline Target-present & Related & $29(3)$ & $24(5)$ & $19(2)$ \\
& Unrelated & $17(3)$ & $22(3)$ & $15(6)$ \\
Target-absent & Related & $32(7)$ & $30(4)$ & $33(5)$ \\
& Unrelated & $25(2)$ & $26(3)$ & $28(3)$ \\
\hline
\end{tabular}

Table A1

List of materials with association norms provided in parentheses for targetcompetitor and target-associate pairs.

\begin{tabular}{lll}
\hline Target & Related competitor & Related associate \\
\hline Arrow & Bullet $(0.01)$ & Bow $(0.35)$ \\
Bird & Fish $(0.01)$ & Feather $(0.40)$ \\
Cigarette & Pipe $(0.01)$ & Ashtray $(0.01)$ \\
Comb & Brush $(0.17)$ & Hair $(0.61)$ \\
Crown & Scepter $(0.01)$ & King $(0.21)$ \\
Hammer & Drill $(0)$ & Nail $(0.28)$ \\
Hand & Foot $(0.18)$ & Finger $(0.18)$ \\
Lock & Hinge $(0)$ & Key $(0.45)$ \\
Nose & Eye $(0.06)$ & Face $(0.16)$ \\
Organ & Tuba $(0)$ & Church $(0.10)$ \\
Plane & Ship $(0.01)$ & Propeller $(0)^{\mathrm{a}}$ \\
Racquet & Bat $(0.02)$ & Shuttlecock $(0)^{\mathrm{a}}$ \\
Saddle & Horseshoe $(0)$ & Horse $(0.64)$ \\
Shirt & Trousers $(0.04)$ & Tie $(0.16)$ \\
Screw & Hook $(0)$ & Screwdriver $(0.01)$ \\
Thread & Rope $(0)$ & Needle $(0.61)$ \\
\hline
\end{tabular}

Fillers: torch, swan, tie, lollypop, pear, bell, cloud, football, card, mouse, plaster, flower, weight, belt, butterfly, broom.

a Non-existing association norms set to zero.

to distractors across target-present and absent trials, the interaction between distractor condition and sub-group failed to reach significance $\left(F(1,7)=4.85, p=0.063, \eta^{2}=0.41\right)$, although there was a trend for an increased proportion of first gazes to the related distractors by the AC/AT patients compared to the lateral sub-group (the difference in the percentage of first gazes to related compared with unrelated distractors was $9 \%$ for the AC/AT patients versus $3 \%$ for the other patients; see Table 3 ). The difference in the proportion of first gazes to related and unrelated distractors for the age-matched control participants was $4 \%$. Neither the AC/AT nor the lateral sub-group of patients differed from the controls (AC/AT versus controls: $F(1,10)=2.40, p=0.152$, $\eta^{2}=0.19$; Lateral versus controls: $F(1,13)=0.37, p=0.850$, $\eta^{2}=0.03$ )

These data again indicate that the patients were particularly impaired at a post-selection stage of target identification, rather than semantic relatedness exerting an abnormally strong 'pull' on attention. We suggest that when attention is drawn to a related distractor and it is selected, it may activate a target-present response. This would then create response conflict on target-absent trials. This problem due to response conflict may be exacerbated in patients with $\mathrm{AC} / \mathrm{AT}$ damage, given the link between the $\mathrm{AC}$ and error monitoring (Blasi et al., 2006; Carter et al., 1998). Note that, for the AC/AT patients, the effect of distractor relatedness on errors was about four times larger on target-absent trials than on target-present trials. Evidence consistent with the argument for response priming taking place comes from the data on gaze durations to targets, which were shorter (across both patients and controls) when the related distractor was present relative to when it was absent. In this case, priming of a target-present respons2e from the related distractor would reduce the time taken before a response was made.

\section{Conclusions}

The data indicate that patients with frontal-lobe lesions can have problems at two stages of visual search: (i) impaired selection of targets in relation to both related and unrelated distractors, and (ii) impairments in rejecting semantically related distractors at a post-selection stage of target identification. The data fit with the proposal that the frontal lobes help to specify the target for search and to keep separate the re-presentation of task-relevant targets from activated re-presentations of other items. In addition, the AC may play a particular role in monitoring conflict when distractors prime responses that are at variance with the response required in the search task.

\section{Acknowledgments}

This work was supported by grants from the BBSRC, ESRC, MRC (UK) and the EU.

\section{Appendix A}

See Table A1.

\section{References}

Alario, F.-X., Segui, J., \& Ferrand, L. (2000). Semantic and associative priming in picture naming. The Quarterly Journal of Experimental Psychology, 53A, 741-764.

Belke, E., Humphreys, G. W., Watson, D. G., Meyer, A. S., \& Telling, A. L. (2008). Topdown effects of semantic knowledge in visual search are modulated by cognitive but not perceptual load. Perception \& Psychophysics, 70(8), 1444-1458.

Blasi, G., Goldberg, T. E., Weickert, T., Das, S., Kohn, P., Zoltick, B., et al. (2006). Brain regions underlying response inhibition and interference monitoring and suppression. European Journal of Neuroscience, 23(6), 1658-1664.

Burgess, P. W., \& Shallice, T. (1997). The hayling and brixton tests. Suffolk, England: Thames Valley Test Company.

Carter, C. S., Braver, T. S., Barch, D. M., Botvinick, M. M., Noll, D., \& Cohen, J. D. (1998). Anterior cingulate cortex, error detection, and the online monitoring of performance. Science, 280(5364), 747-749.

Chelazzi, L., Miller, E. K., Duncan, J., \& Desimone, R. (1993). A neural basis for visualsearch in inferior temporal cortex. Nature, 363(6427), 345-347.

Corbetta, M., \& Shulman, G. L. (2002). Control of goal-driven and stimulus-driven attention in the brain. Nature Reviews Neuroscience, 3(3), 201-215.

De Fockert, J. W., Rees, G., Frith, C. D., \& Lavie, N. (2004). Neural correlates of attentional capture in visual search. Journal of Cognitive Neuroscience, 16(5), 751-759.

Donner, T., Kettermann, A., Diesch, E., Ostendorf, F., Villringer, A., \& Brandt, S. A. (2000). Involvement of the human frontal eye field and multiple parietal areas in covert visual selection during conjunction search. European Journal of Neuroscience, 12(9), 3407-3414.

Duncan, J., \& Humphreys, G. W. (1989). Visual-search and stimulus similarity. Psychological Review, 96, 433-458.

Gado, M., Hanaway, J., \& Frank, R. (1979). Functional-anatomy of the cerebral-cortex by computed tomography. Journal of Computer Assisted Tomography, 3(1), 1-19.

Hodsoll, J. P., \& Humphreys, G. W. (2001). Driving attention with the top down: The relative contribution of target templates to the linear separability effect in the size dimension. Perception E' Psychophysics, 63(5), 918-926.

Hodsoll, J. P., \& Humphreys, G. W. (2005). The effect of target foreknowledge on visual search for categorically separable orientation targets. Vision Research, 45(18), 2346-2351.

Howard, H., \& Patterson, K. (1992). Pyramids and palm trees. Thames Valley Test Company.

Humphreys, G. W., \& Forde, E. M. E. (2005). Naming a giraffe but not an animal: Base-level but not super-ordinate naming in a patient with impaired semantics. Cognitive Neuropsychology, 22, 539-558.

Humphreys, G. W., Hodsoll, J. P., \& Riddoch, R. J. (2009). Fractionating the binding process: Neuropsychological evidence from reversed search efficiencies. Journal of Experimental Psychology: Human Perception and Performance, 35(3), 627-647.

Humphreys, G. W., \& Riddoch, M. J. (2003). A case series analysis of categoryspecific deficits for living things. Cognitive Neuropsychology, 20(3-6), 263-306.

Kanwisher, N., \& Wojciulik, E. (2000). Visual attention: Insights from brain imaging. Nature Reviews Neuroscience, 1, 91-100.

Kiss, G. R., Armstrong, C., Milroy, R., \& Piper, J. (1973). An associative thesaurus of English and its computer analysis. In A. J. Aitken, R. W. Bailey, \& N. HamiltonSmith (Eds.), The computer and literary studies (pp. 153-165). Edinburgh: University Press.

Kumada, T., \& Hayashi, M. (2006). Deficits in feature-based control of attention in a patient with a right fronto-temporal lesion. Cognitive Neuropsychology, 23(3), 401-423. 
Lavie, N., \& De Fockert, J. (2006). Frontal control of attentional capture in visual search. Visual Cognition, 14, 863-876.

Moores, E., Laiti, L., \& Chelazzi, L. (2003). Associative knowledge controls deployment of visual selective attention. Nature Neuroscience, 6, 182-189.

Muggleton, N. G., Juan, C. H., Cowey, A., \& Walsh, V. (2003). Human frontal eye fields and visual search. Journal of Neurophysiology, 89(6), 3340-3343.

Nelson, H. E., \& Willison, J. R. (1991). Restandardisation of the NART against the WAIS$R$. Windsor: NFER Nelson.

Perea, M., \& Rosa, E. (2002). The effects of associative and semantic priming in the lexical decision task. Psychological Research, 66, 180-194.

Snodgrass, J. G., \& Vanderwart, M. (1980). A standardized set of 260 pictures: Norms for name agreement, image agreement, familiarity, and visual complexity. Journal of Experimental Psychology: Human Learning E' Memory, 6, 174-215.

Soto, D., Humphreys, G. W., \& Heinke, D. (2006). Dividing the mind: The necessary role of the frontal lobes in separating memory from search. Neuropsychologia, 44(8), 1282-1289.
Telling, A. L. (2008). Semantic and phonological context effects in visual search Unpublished doctoral dissertation, University of Birmingham, Birmingham, UK.

Thompson-Schill, S. L., Swick, D., Farah, M. J., D’Esposito, M., Kan, I. P., \& Knight, R. T. (1998). Verb generation in patients with focal frontal lesions: A neuropsychological test of neuroimaging findings. Proceedings of the National Academy of Sciences, USA, 95, 15855-15860.

Walker, R., Husain, M., Hodgson, T. L., Harrison, J., \& Kennard, C. (1998). Saccadic eye movement and working memory deficits following damage to human prefrontal cortex. Neuropsychologia, 36(11), 1141-1159.

Wheeldon, L. R., \& Monsell, S. (1994). Inhibition of spoken word production by priming a semantic competitor. Journal of Memory and Language, 33, 332-356.

Wolfe, J. M. (1998). Visual Search. In H. Pashler (Ed.), Attention (pp. 13-74). Hove UK: Psychology Press Ltd.

Zihl, J., \& Hebel, N. (1997). Patterns of occulomotor scanning in patients with unilateral posterior parietal or frontal lobe damage. Neuropsychologia, 35(9), 893-906. 